\title{
Acetaminophen administration in pediatric age: an observational prospective cross- sectional study
}

\author{
Riccardo Lubrano ${ }^{1}$, Sara Paoli ${ }^{1}$, Marco Bonci ${ }^{2}$, Luigi Di Ruzza ${ }^{3}$, Corrado Cecchetti ${ }^{4}$, Raffaele Falsaperla ${ }^{5}$, \\ Piero Pavone ${ }^{5}$, Nassim Matin ${ }^{6}$, Giovanna Vitaliti ${ }^{1,7^{*}}$ and Isotta Gentile ${ }^{1}$
}

\begin{abstract}
Background: Parents often do not consider fever as an important physiological response and mechanism of defense against infections that leads to inappropriate use of antipyretics and potentially dangerous side effects. This study is designed to evaluate the appropriateness of antipyretics dosages generally administered to children with fever, and to identify factors that may influence dosage accuracy.

Results: In this cross-sectional study we analyzed the clinical records of 1397 children aged $>1$ month and $<16$ years, requiring a primary care (ambulatory) outpatient visit due to fever. We evaluated the number of children who had received $>90 \mathrm{mg} / \mathrm{kg} /$ day of acetaminophen, the prescriber, the medication formula and the educational level of the caregiver who administered acetaminophen. Among those children included in our study, $74 \%$ were administered acetaminophen for body temperature $\leq 38.4{ }^{\circ} \mathrm{C} .24 .12 \%$ of children received $>90 \mathrm{mg} / \mathrm{kg} /$ day of acetaminophen. Parents with university qualifications most commonly self-administered acetaminophen to their children, in a higher than standard dose. Self medication was also described in $60 \%$ of children, whose acetaminophen was administered for temperatures $<38^{\circ} \mathrm{C}$. Acetaminophen over-dosage was also favored by the use of drug formulations as drops or syrup.

Conclusions: Our study shows that preventive action should be taken regarding the use of acetaminophen as antipyretic drug in children in order to reduce the fever phobia and self-prescription, especially of caregivers with higher educational levels. It is also necessary to promote a more appropriate use of acetaminophen in those parents using drops or syrup formulations.
\end{abstract}

Keywords: Children, Off label, Supratherapeutic dose, Acetaminophen, Prescription, Educational level

\section{Background}

In recent years a fever phobia phenomenon [1] has been recognized among parents, who consider fever as a health danger instead of an important physiologic response and a mechanism of defense against infections [2, 3].

This phenomenon, associated with an increase in selfmedication [4] has resulted in inappropriate use of antipyretics, amongst which the most commonly used is acetaminophen $[5,6]$.

\footnotetext{
* Correspondence: giovitaliti@yahoo.it

'Department of Pediatrics, La Sapienza University of Rome, Rome, Italy ${ }^{7}$ AOU Policlinico-OVE, University of Catania, Via Plebiscito n. 628, 95100 Catania, Italy

Full list of author information is available at the end of the article
}

The dosage of acetaminophen in children is assessed according to weight [7]; thus a wrong weight measurement or wrong perception of the child's weight can lead to inappropriate medication dosing. Also, dosing based on age may cause errors in overweight or underweight children [8-10].

Actually, the appropriate dosage of acetaminophen in children is $10-15 \mathrm{mg} / \mathrm{kg} /$ dose administered every $4-6 \mathrm{~h}$ [11]. Higher doses of acetaminophen may be hepatotoxic, thus its administration should be performed carefully. Acetaminophen toxicity may be consequent to the administration of higher dosages both for over-dosages (in terms of quantity per dose) and more frequent standard doses (in terms of frequencies) of acetaminophen or excessive in numbers of administrations per day in $24 \mathrm{~h}$, causing a daily overdose 
of $>90 \mathrm{mg} / \mathrm{kg} /$ day [11-17]. Other authors $[14,18]$ have described adverse effects even with doses of $75 \mathrm{mg} / \mathrm{kg} /$ day, however they were not able to clarify what conditions may be responsible for the onset of toxicity in some children, while the same doses have been shown not to be toxic for matched groups of patients. In regards, the Italian Society of Pediatrics suggest the daily maximal dose of acetaminophen of $80 \mathrm{mg} / \mathrm{kg} /$ day, defining toxic a dose of $150 \mathrm{mg} / \mathrm{Kg}$ [19].

The pediatric acute and emergency departments are privileged areas to observe how acetaminophen is used by caregivers in cases of fever. The study was performed on children admitted to the acute care and emergency departments of some Hospitals in the Lazio region. The objective of our study was to evaluate the appropriateness of the dosage of acetaminophen generally administered to children with fever, and the factors that may influence dosage accuracy.

\section{Methods}

We performed an observational cross-sectional study in a period of six months, in accordance with STROBE guidelines [20] from November 2012 to April 2013.

The study setting is made of three health care services (General Paediatrics Operative Unit, Grassi Hospital of Rome, Policlinico Umberto I of Frosinone and General Paediatrics Operative Unit, Vittorio-Emanuele Hospital, Catania) affiliated to SIMEUP (Italian Society for Pediatric Emergency). Children aged between 1 month and 16 years, who required a primary care outpatient visit due to fever, to whom acetaminophen was administered by caregivers as antipyretic drug, from almost $24 \mathrm{~h}$, were enrolled in this study.

In the pediatric emergency department, caregivers were asked to respond to a questionnaire inquiring on: the age and weight of the child, if acetaminophen was administered before entering the hospital, the dosage and frequency of administration, type of medication: liquid (syrup or drops) or solid (suppositories or tablets), the underlying body temperature that prompted the administration of medication, if other antipyretic drugs had been administered before, parent's nationality, the parent giving the medication, level of education, and the name of the prescriber. At questionnaire administration, a healthcare physician explained how to fill the form to the parents.

Exclusion criteria were applied to the following categories:

- Children with fever to whom no antipyretic drug was administered

- Children with fever to whom acetaminophen was not administered as antipyretic

- Children taking antipyretics other than acetaminophen,

- Children with incomplete questionnaires,
- Children whose parents were of different nationalities (for example one Italian and one with a foreign nationality). These patients were excluded to reduce the potential for bias related to different cultural behaviors.

The primary outcome of the study was to evaluate the dosage of acetaminophen administered both as $\mathrm{mg} / \mathrm{kg} /$ dose and as total daily quantity in $\mathrm{mg} / \mathrm{kg} /$ day. Dosage of up to $15 \mathrm{mg} / \mathrm{kg} /$ dose (group A) was considered normal. Dosage of more than $15 \mathrm{mg} / \mathrm{kg} /$ dose (group B) was considered as supratherapeutic [11, 14]. Also the daily quantity $\left(\mathrm{mg} / \mathrm{kg} /\right.$ dose $\times \mathrm{n}^{\circ}$ of doses) was considered as not potentially dangerous if $<90 \mathrm{mg} / \mathrm{kg} / \mathrm{die}$ (group C) or potentially dangerous if $>90 \mathrm{mg} / \mathrm{kg} /$ day (group D), [11].

Secondary outcomes were the temperature for which antipyretics were used and the factors that could influence medication's dosages, such as:

- Educational level of the caregiver who administered acetaminophen to the child (elementary school, primary school, secondary school, university education)

- Type of prescription: medical or self-prescription

- Pharmaceutical formulation: liquid, drops or syrup, (DSy group) or solid, tablets or suppositories, (TSu group).

- Parents nationality, differentiating couples of parents as Italians (I) and Foreigners (F)

\section{Statistics}

Data is analyzed with JMP 10 for mac.

Chi-square was used for differences between groups of categorical variables.

Wilcoxon test was used for analyzing the differences between different quantities of acetaminophen. Because estimating, initially, the approximation of population distribution to normal by Kolmogorov-Smirnov One-Sample Test and statistics for kurtosis and symmetry, it was asymmetrically distributed and non-parametric tests were used. Results for each studied group were expressed as median/3 rd quartile/1 st quartile

A $p$ value of $<0.05$ is considered as statistically significant.

Also, a contingency analysis was used to verify the distribution of patients with respect to the caregivers' nationality and the daily dose of administered acetaminophen.

\section{Study approval}

The protocol conforms to the ethical guidelines of the 1975 Declaration of Helsinki as revised in year 2000, and was approved by the institution's ethical committee [21]. 


\section{Results}

A total of 2108 children who were admitted to Acute and Emergency Departments because of fever were selected for this study. At baseline 203 children to whom no antipyretic drug was administered were excluded. Also 108 children, who used other antipyretic drugs and 95 children who assumed acetaminophen plus another different antipyretic drug were excluded. Parents of those children included in the study were asked to fill an evaluation questionnaire. After collecting questionnaires, 289 children were excluded as their parents did not fully fill the questionnaire. Sixteen other children were also excluded because their caregivers' questionnaire showed that their parents were of different nationality. Thus, a total of 1397 questionnaires were analyzed. Median age of children was 72 months (with 3 rd quartile of 118 months and 1 st quartile of 48 months).

Acetaminophen was administered in $74 \%$ of cases to children with a body temperature below $38.4{ }^{\circ} \mathrm{C}$ (Fig. 1).

As shown in Table 1, the daily dose of acetaminophen was $<90 \mathrm{mg} / \mathrm{kg} /$ day (group C) in 1060 (75.88 \%) cases and $>90 \mathrm{mg} / \mathrm{kg} /$ day (group D) in 337 (24.12\%) cases.

Among those who assumed more than $90 \mathrm{mg} / \mathrm{kg} /$ day (group D), Acetaminophen was administered more than $15 \mathrm{mg} / \mathrm{kg} /$ dose in $97.63 \%$, while the remaining $2.37 \%$ received less than $15 \mathrm{mg} / \mathrm{kg} /$ dose, with a higher frequency with respect to standard during the $24 \mathrm{~h}$ (Table 1 ).

Data on Table 2 shows that in group $C$ (daily dose $<90 \mathrm{mg} / \mathrm{kg} /$ day), the educational level of the caregiver who administered acetaminophen to his/her child, was secondary education in $63 \%$ cases, primary education in $33 \%$ and an elementary education in $4 \%$, while in group D (daily dose $>90 \mathrm{mg} / \mathrm{kg} /$ day) was university degree in $71 \%$ of cases and a secondary degree in $29 \%$. As a matter of fact Table 2 shows that the caregiver responsible for the administration of higher daily doses of acetaminophen is the one with a higher educational level (caregiver with a university degree: dose/day $121.73 \pm 22.89 \mathrm{mg}$ ).

Acetaminophen was administered as tablets or suppositories (group TSu) in $87.97 \%$ of children and drops or syrup (group DSy) in $12.03 \%$. The daily dose of acetaminophen $(\mathrm{mg} / \mathrm{kg} /$ day) was significantly higher in those who assumed drops or syrup rather than those who assumed tablets or suppositories, both for children in group C (dose/day $<90 \mathrm{mg} / \mathrm{kg} /$ day) [the dose is expressed as median (3 rd quartile/1 sd quartile)], [DSy vs TSu: 69.81 $(80.97 / 52.63)$ vs $57.69(71.91 / 44.44) p<0.003$; DSy $5 \%$, TSu $95 \%$ ] and those in group D (dose/day > $90 \mathrm{mg} / \mathrm{kg} / \mathrm{die}$ ) [DSy vs TSu: 117.65 (133.33/100) vs 105.63 (116.28/96.38) $p<0.0001$; DSy 35 \%, TSu 65 \%]. Moreover, odds ratio revealed a higher risk of acetaminophen overdose when drops and/or syrup formulations were used, $O R=0.089$ (lower $95 \%=0.061$ Upper $95 \%=0.13$ )
Finally, acetaminophen was prescribed by a health professional for $85.7 \%$ of children, while for $14.3 \%$ of children acetaminophen was self-prescribed by parents, the latter all included in group D (dose/day $>90 \mathrm{mg} / \mathrm{kg} /$ day). Consequently, acetaminophen overdose was detected in $9.82 \%$ of children, even with a medical prescription (Table 1).

As highlighted by the contingency analysis in Table 3, the caregivers' nationality to whom acetaminophen was prescribed, was equally distributed between Italians (I) and Foreigners (F) both in group C (dose/day $<90 \mathrm{mg} / \mathrm{kg} /$ day) and in group D (dose/day $>90 \mathrm{mg} / \mathrm{kg} /$ day). No statistically significant differences have been observed, with respect to nationality, between those patients assuming doses $<$ or $>90 \mathrm{mg} / \mathrm{kg} /$ day of acetaminophen (Chi-square test $\mathrm{p}$ NS). Moreover, the dose/day evaluation according to the nationality of the caregivers who administered the drug has not shown any statistically significant difference between group $\mathrm{C}$ and $\mathrm{D}$. Also, the odds ratio analysis has not shown a significant risk with respect to caregivers' nationality, $O R=0.80$ (lower $95 \%=0.56$, upper $95 \%=1.14$ )

Finally, a specific analysis was performed for those children who were treated with acetaminophen for body temperatures under $38{ }^{\circ} \mathrm{C}$. These represented $21 \%$ of the included children (293 patients), with a median age of 75 months, (a 3rd quartile of 106 months and 1 st quartile of 53 months), in whom the parent administering the drug had secondary education in $52 \%$ of cases. Among these patients, $72 \%$ consumed less than $90 \mathrm{mg} / \mathrm{kg} /$ day, prescribed by a doctor only in $40 \%$ of cases. This percentage was significantly lower than patients with fever over $38^{\circ} \mathrm{C}$ (Chi-square test $\left.p<0.01\right)$.

\section{Discussion}

In this study, we indicated that $74 \%$ of caregivers start antipyretics at temperatures $<38,4{ }^{\circ} \mathrm{C}$. Among them, $71.57 \%$ administer it between 38 and $38.4{ }^{\circ} \mathrm{C}$, and $21.00 \%$ under $38{ }^{\circ} \mathrm{C}$ (Fig. 1). This attitude surely reflects a widespread fever phobia that leads to early antipyretic administration. Literature data have already described this attitude among caregivers and pediatricians [22-24], justified by the attempt of reducing the discomfort generated by fever. This therapeutic attitude is in contrast with other guidelines indicating pharmacological treatment when temperature is $>40{ }^{\circ} \mathrm{C}$ or $>39{ }^{\circ} \mathrm{C}$ if the child is in discomfort [25].

Moreover about $24.12 \%$ of our patients assumed a daily dose of acetaminophen higher than $90 \mathrm{mg} / \mathrm{kg} /$ day, of which in $97.63 \%$ of cases a high quantity of drug was administered in a single daily dose, and not a higher frequency of administration (Table 1), as opposed to what was described in a study by James et al [26]. The assumption of higher doses of self-prescribed acetaminophen by the caregiver was $14.3 \%$ in the studied population. 


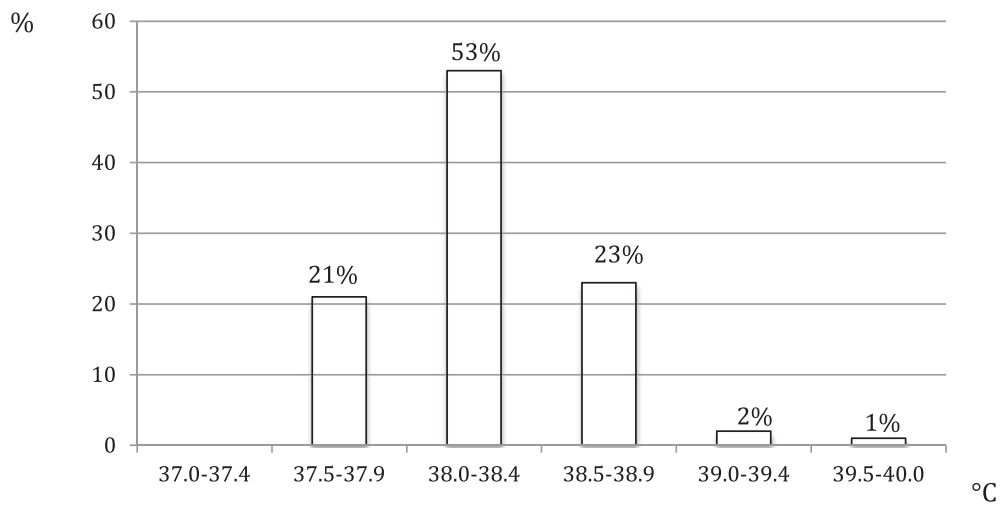

Fig. 1 Body temperature to which the parents reported to have begun to treat the fever

This attitude of autonomous choices was more frequent in those caregivers with a higher level of education who should have better understood that acetaminophen is effectively a drug and not just an over-the-counter product, avoiding its superficial use, as evidenced by McCloskey et al [27]. This behavior has also been described in healthcare students, in which their higher knowledge on drugs seems to favor the phenomenon of self-medication [28]. Self-prescription phenomena strictly relate to the administration of high dosages of acetaminophen [1, 29].

In our study self-medication was detected in $60 \%$ of children to whom acetaminophen was administered for body temperature $<38{ }^{\circ} \mathrm{C}$, but with doses $<90 \mathrm{mg} / \mathrm{kg} /$ day in $72 \%$ of cases.

The results of our study also highlight the preventive efficient role of the general practioners in the education for the right prescription and assumption of acetaminophen in

Table 1 Subgroups of the studied population accordingly to the total daily dose (group D > 90 mg/kg/day; Group C <90 mg/kg/die) and the single daily dose (group A $<15$ mg/kg/dose; group B $>15$ mg/kg/dose;) of assumed acetaminophen

\begin{tabular}{|c|c|c|c|c|c|c|c|c|}
\hline \multirow[t]{4}{*}{ Group dose/day } & \multirow[t]{4}{*}{ N (\%) } & \multirow{4}{*}{$\begin{array}{l}\text { Medical } \\
\text { prescription/ } \\
\text { self-prescription } \\
\% / \%\end{array}$} & $\mathrm{mg} / \mathrm{kg} /$ day & \multirow[t]{4}{*}{ Sub-group dose } & \multirow[t]{4}{*}{ N (\%) } & $\mathrm{mg} / \mathrm{kg} / \mathrm{dose}$ & N. of doses & $\mathrm{mg} / \mathrm{kg} / \mathrm{day}$ \\
\hline & & & Median & & & Median & Median & Median \\
\hline & & & 3 rd quartile & & & 3 rd quartile & 3 rd quartile & 3 rd quartile \\
\hline & & & 1 st quartile & & & 1 st quartile & 1 st quartile & 1 st quartile \\
\hline \multirow[t]{3}{*}{ Group D } & \multirow[t]{6}{*}{$337(24.12)$} & \multirow[t]{6}{*}{$9,82 / 14.3$} & 107.14 & \multirow[t]{3}{*}{$<15 \mathrm{mg} / \mathrm{kg} /$ dose (Group A) } & \multirow[t]{3}{*}{$8(2.37)$} & 13.39 & 8.00 & 107.10 \\
\hline & & & & & & 14.76 & 8.00 & 118.10 \\
\hline & & & 123.71 & & & 11.94 & 8.00 & 95.52 \\
\hline \multirow[t]{3}{*}{$>90$ mg/kg/day } & & & & \multirow[t]{3}{*}{$>15$ mg/kg/dose (Group B) } & \multirow[t]{3}{*}{$329(97.63)$} & 19.53 & 6.00 & 107.14 \\
\hline & & & 97.61 & & & 22.73 & 6.00 & 123.97 \\
\hline & & & & & & 17.24 & 5.00 & 97.66 \\
\hline \multirow[t]{3}{*}{ Group C } & \multirow[t]{6}{*}{$1060(75.88)$} & \multirow[t]{6}{*}{$75.88 / 0$} & 58.20 & \multirow[t]{3}{*}{$<15 \mathrm{mg} / \mathrm{kg} /$ dose (Group A) } & \multirow[t]{3}{*}{$703(66.32)$} & 11.68 & 4.00 & 52.63 \\
\hline & & & & & & 13.44 & 6.00 & 68.18 \\
\hline & & & 73.13 & & & 9.62 & 4.00 & 39.06 \\
\hline \multirow[t]{3}{*}{$<90$ mg/kg/day } & & & 44.78 & $>15$ mg/kg/dose (Group B) & 357 (33.68) & 18.11 & 4.00 & 68.96 \\
\hline & & & & & & 20.00 & 4.00 & 76.92 \\
\hline & & & & & & 16.67 & 3.00 & 61.68 \\
\hline
\end{tabular}

Group D vs C (mg/kg/day) $p<0.001$

Group D: Sub-group A vs Sub-group

$\mathrm{mg} / \mathrm{kg} /$ dose $p<0.0001$; number of doses $p<0.0001 ; \mathrm{mg} / \mathrm{kg} /$ day $\mathrm{p} \mathrm{NS}$

Group C: Sub-group A vs Sub-group B

$\mathrm{mg} / \mathrm{kg} /$ dose $p<0.0001 ;$ number of doses $p<0.0001 ; \mathrm{mg} / \mathrm{kg} /$ day $p<0.0001$

$\mathrm{mg} / \mathrm{kg} /$ dose for $C$ vs $D$ sub-groups

$C A$ vs $D B ; D B$ vs $C B ; D A$ vs $C B p<0.0001-D A$ vs $C A p$ NS

Number of doses for $C$ vs $D$ sub-groups

$C A$ vs DB; DB vs CB; DA vs CB; DA vs CA $p<0.0001$

$\mathrm{mg} / \mathrm{kg} /$ day for $C$ vs $D$ sub-groups

CA vs DB; DB vs CB; DA vs CB; DA vs CA $p<0.0001$ 
Table 2 Influence of the level of education on the total daily dose of administered acetaminophen

\begin{tabular}{|c|c|c|c|c|c|}
\hline \multirow[b]{2}{*}{ Level of education } & \multicolumn{3}{|l|}{$\begin{array}{l}\text { Group C } \\
<90 \mathrm{mg} / \mathrm{kg} / \text { day }\end{array}$} & \multicolumn{2}{|l|}{$\begin{array}{l}\text { Group D } \\
>90 \mathrm{mg} / \mathrm{kg} / \text { day }\end{array}$} \\
\hline & Elementary school & Primary education & Secondary education & Secondary education & University education \\
\hline Number & 44 & 347 & 669 & 98 & 239 \\
\hline$\%$ in the group & 4 & 33 & 63 & 29 & 71 \\
\hline$\%$ of the total population & 3.15 & 24.84 & 47.88 & 7.01 & 17.11 \\
\hline Dose/day mg/kg/die & $21.47 / 23.94 / 17.51$ & $41.67 / 46.58 / 35.71$ & $69.44 / 77.40 / 60.42$ & $93.75 / 96.65 / 92.98$ & $115.38 / 128.20 / 107.14$ \\
\hline
\end{tabular}

Dose/day = median/ 3 rd quartile/1 st quartile

$C$ group $C, D$ group $D$

El Elementary school, $P$ primary education, $S$ secondary education, $U$ University education

El vs P; El vs S-C; El vs S-D; S-D vs U; P vs S-C; P vs S-D; P vs U; S-C vs S-D; S-D vs U all $p<0.0001$

childhood. In fact all the patients assuming a proper dose (less than $90 \mathrm{mg} / \mathrm{kg} /$ day) had a medical prescription and only $9.82 \%$ of the studied population, assumed a dose of more than $90 \mathrm{mg} / \mathrm{kg} /$ day with a medical prescription. This evidence is in contrast with the results of other data which related the problem of acetaminophen overdose to a wrong prescription by the primary care physician [30], as to respond to the anxiety of family members, who seek an immediate resolution of their child's fever [23].

Finally, it is important to mention the assumption of the drug as drops and syrup, (as seen in $12.03 \%$ of the studied population), was associated with extra doses of acetaminophen, as described by other authors, who also proposed the use of simpler systems to better highlight the appropriate dosage of acetaminophen [29-32] .

\section{Conclusions}

We believe that further interventions should be done to improve the knowledge of caregivers on the correct use of acetaminophen. Also the physiological protective role

Table 3 Contingency table of the nationality with respect to the daily dose of total administered acetaminophen. Nationality by group dose/day

\begin{tabular}{llll}
\hline & Group C & Group D & \\
Count & Daily dose & Daily dose & \\
Total \% & $<90 \mathrm{mg} / \mathrm{kg} /$ day & $>90 \mathrm{mg} / \mathrm{kg} /$ day & \\
Col \% & & & 184 \\
Row \% & & 51 & 13,17 \\
\hline Foreing & 133 & 3,65 & \\
& 9,52 & 15,13 & 1213 \\
& 12,55 & 27,72 & 86,83 \\
& 72,28 & 286 & \\
Italian & 927 & 20,47 & 1397 \\
& 66,36 & 84,87 & \\
& 87,45 & 23,58 & \\
& 76,42 & 337 & \\
& 1060 & 24,12 & \\
& 75,88 & & \\
\hline
\end{tabular}

of fever, parent's responsibility in following the pediatrician's prescription precisely, avoiding the self-prescription phenomenon both concerning the timing to start acetaminophen and the administered doses should be emphasized in general population.

\section{Competing interests}

The authors declare that they have no competing interests.

\section{Authors' contributions}

IG: monitored data collection for the whole trial, revised the draft paper. SP: monitored data collection for the whole trial. MB: collection tools, monitored data collection for the whole trial. LDR: collection tools, monitored data collection for the whole trial. CC: revised the draft paper. RF and PP: wrote the statistical analysis plan, cleaned and analysed the data, and revised the paper. VG and NM: worked on revision and editing of the final version of the manuscript. LR: wrote the statistical analysis plan, cleaned and analysed the data, and drafted and revised the paper. All authors read and approved the final manuscript.

\section{Author details}

${ }^{1}$ Department of Pediatrics, La Sapienza University of Rome, Rome, Italy. ${ }^{2}$ Paediatrics Operative Unit, Grassi Hospital, Rome, Italy. ${ }^{3}$ Paediatrics Operative Unit, Policlinico Umberto I, Frosinone, Italy. ${ }^{4}$ Acute and Emergency Operative Unit, Bambino Gesù Paediatric Hospital, Rome, Italy. ${ }^{5}$ General Paediatrics and Acute and Emergency Paediatrics Operative Unit, Vittorio Emanuele University Hospital, Catania, Italy. ${ }^{6}$ University Medical Science of Teheran, University of Teheran, Teheran, Italy. ${ }^{7} \mathrm{AOU}$ Policlinico-OVE, University of Catania, Via Plebiscito n. 628, 95100 Catania, Italy.

Received: 5 November 2015 Accepted: 18 January 2016

Published online: 26 February 2016

\section{References}

1. Poirier MP, Collins EP, McGuire E. Fever phobia: a survey of caregivers of children seen in a pediatric emergency department. Clin Pediatr. 2010;49:530-4.

2. Powell K. Fever. In: Nelson textbook of pediatrics. 17th ed. Philadelphia: Saunders; 2004. p. 839-41.

3. de Martino $M$, Chiarugi A. Recent Advances in Pediatric Use of Oral Paracetamol in Fever and Pain Management. Pain Ther. 2015;4(2):149-68. doi:10.1007/s40122-015-0040-z. Epub 2015 Oct 30.

4. Allotey P, Reidpath DD, Elisha D. "Social medication" and the control of children: a qualitative study of over the counter medication among Australian children. Pediatrics. 2004;114:378-83.

5. Russell FM, Shann F, Curtis N, Mulholland K. Evidence on the use of paracetamol in febrile children. Bull World Health Organ. 2003;81(5):367-72. Epub 2003 Jul 7.

6. Betz MG, Grunfeld AF. 'Fever phobia' in the emergency department: a survey of children's caregivers. Eur J Emerg Med. 2006;13:129-33.

7. Lenney W. Paracetamol prescription by age or by weight? Arch Dis Child. 2012;97:277-8.

8. de Bont EG, Loonen N, Hendrix DA, Lepot JM, Dinant GJ, Cals JW Childhood fever: a qualitative study on parents' expectations and experiences during general practice out-of-hours care consultations. BMC Fam Pract. 2015;16(1):131. doi:10.1186/s12875-015-0348-0. 
9. Eyers S, Fingleton J, Eastwood A, Perrin K, Beasley R. British National Formulary for Children: the risk of inappropriate acetaminophen prescribing. Arch Dis Child. 2012;97:279-82.

10. Li SF, Lacher B, Crain EF. Acetaminophen and ibuprofen dosing by parents. Pediatr Emerg Care. 2000;16:394-7.

11. Sullivan JE, Farrar HC, the Section on Clinical Pharmacology and Therapeutics and Committee on Drugs. Fever and antipyretic use in children. Pediatrics. 2011;127:580-7.

12. American Academy of Pediatrics. Committee on drugs. Acetaminophen toxicity in children. Pediatrics. 2001;108:1020-4.

13. Li C, Martin BC. Trends in emergency department visits attributable to acetaminophen overdoses in the United States: 1993-2007. Pharmacoepidemiol Drug Saf. 2011;20:810-8.

14. Kozer E, Greenberg R, Zimmerman DR, Berkovitch M. Repeated supratherapeutic doses of acetaminophen in children a literature review and suggested clinical approach. Acta Paediatr. 2006;95:1165-71.

15. Shivbalan S, Sathiyasekeran M, Thomas K. Therapeutic misadventure with acetaminophen in children. Indian J Pharmacol. 2010;42:412-5.

16. Kearns GL, Leeder JS, Wasserman GS. Acetaminophen intoxication during treatment: what you don't know can hurt you. Clin Pediatr. 2000:39:133-44.

17. Lavonas EJ, Reynolds KM, Dart RC. Therapeutic acetaminophene is not associated with liver injury in children: a systematic review. Pediatrics. 2010;126:e1430-44.

18. Heard K, Bul A, Miynarchek SL, Green JL, Bond GR, Clark RF, et al. Toxicity from repeated doses of acetaminophen in children: assessment of causality and dose in reported cases. Am J Ther. 2014;21:174-83.

19. Chiappini E, Principi N, Longhi R, Tovo PA, Becherucci P, Bonsignori F, Esposito $S$, et al. Management of fever in children: summary of the Italian Pediatric Society guidelines. Clin Ther. 2009;31(8):1826-43. doi:10.1016/j. clinthera.2009.08.006.

20. Von Elm E, Altman DG, Egger M, Pocock SJ, Gøtzsche PC, Vandenbroucke JP, et al. The Strengthening the Reporting of Observational Studies in Epidemiology (STROBE) statement: guidelines for reporting observational studies. J Clin Epidemiol. 2008:61:344-9.

21. World Medical Association Declaration of Helsinki: ethical principles for medical research involving human subjects. JAMA. 2000;284:3043-5.

22. Chiappini E, Parretti A, Becherucci P, Pierattelli M, Bonsignori F, Galli L, et al. Parental and medical knowledge and management of fever in Italian Pre-school children. BMC Pediatr. 2012;12:97.

23. Lava SA, Simonetti GD, Ramelli GP, Tschumi S, Bianchetti MG. Symptomatic management of fever by Swiss Board-certified pediatricians: results from a cross sectional. Web-based survey. Clin Ther. 2012;34:250-6.

24. May A, Bauchner H. Fever phobia:the pediatrician's contribution. Pediatrics. 1992;90:851-4.

25. Walsh A, Edwards H. Management of childhood fever by parents: literature review. J Adv Nurs. 2006;54:217-27

26. James $L$, Sullivan JE, Roberts D. The proper use of acetaminophen. Pediatr Child Health. 2011;16(9):544-7.

27. McCloskey K, Cranswick N, Connell T. Use of acetaminophen and ibuprofen in children in a tertiary care hospital: are we becoming complacent? Arch Dis Child. 2012:97:181.

28. Correa Da Silva MG, Soares MCF, Muccillo-Baisch AL. Self-medication in university students from the city of Rio Grande, Brazil. BMC Public Health. 2012;12:339.

29. Yin HS, Mendelsohn AL, Wolf MS, Parker RM, Fierman A, van Schaick $L$, et al. Parents' medication administration errors: role of dosing instruments and health literacy. Arch Pediatr Adolesc Med. 2010;164:181-6.

30. Kazouini A, Mohammed BS, Simpson CR, Helms PJ, McLay JS. Acetaminophen prescribing in primary care: too little and too much? Clin Pharmacol. 2011;72:500-4

31. Yin HS, Mendelsohn AL, Fierman A, van Schaick L, Bazan IS, Dreyer BP. Use a pictographic diagram to decrease parent dosing errors with infant acetaminophen: a health literacy perspective. Acad Pediatr. 2011;11:50-7.

32. Wolf MS, King J, Jacobson K, Di Francesco L, Bailey SC, Mullen R, et al. Risk of unintentional overdose with non-prescription acetaminophen products. J Gen Intern Med. 2012;27:1587-93.

\section{Submit your next manuscript to BioMed Central and we will help you at every step:}

- We accept pre-submission inquiries

- Our selector tool helps you to find the most relevant journal

- We provide round the clock customer support

- Convenient online submission

- Thorough peer review

- Inclusion in PubMed and all major indexing services

- Maximum visibility for your research

Submit your manuscript at www.biomedcentral.com/submit
Biomed Central 